Eurostudia

\title{
Lire Musil en sociologue Introduction
}

\section{Barbara Thériault}

Volume 9, numéro 1, 2014

Lire Musil en sociologue

Reading Musil as Sociologist

Musil lesen als Soziologe

URI : https://id.erudit.org/iderudit/1026715ar

DOI : https://doi.org/10.7202/1026715ar

Aller au sommaire du numéro

Éditeur(s)

Le Centre canadien d'études allemandes et européennes

ISSN

1718-8946 (numérique)

Découvrir la revue

Citer ce document

Thériault, B. (2014). Lire Musil en sociologue : introduction. Eurostudia, 9(1), v-vii. https://doi.org/10.7202/1026715ar

Tous droits réservés ( Le Centre canadien d'études allemandes et européennes, 2014
Ce document est protégé par la loi sur le droit d'auteur. L'utilisation des services d'Érudit (y compris la reproduction) est assujettie à sa politique d'utilisation que vous pouvez consulter en ligne.

https://apropos.erudit.org/fr/usagers/politique-dutilisation/
Cet article est diffusé et préservé par Érudit.

Érudit est un consortium interuniversitaire sans but lucratif composé de l'Université de Montréal, l'Université Laval et l'Université du Québec à Montréal. Il a pour mission la promotion et la valorisation de la recherche. https://www.erudit.org/fr/ 


\section{Barbara Thériault}

Université de Montréal

Les auteurs de ce numéro se proposent de relire L'Homme sans qualités, sans doute l'un des romans les plus cités de l'histoire de la sociologie. Écrite à partir de 1919 et publiée au fil des deux décennies subséquentes, l'œuvre de Robert Musil (2004 [1930-1941]) nous plonge, par une aventure littéraire, au début du $20^{\mathrm{e}}$ siècle en Europe centrale, au cœur de la « modernité classique » ${ }^{1}$.

L'Homme sans qualités s'ouvre sur un personnage, Ulrich, qui nous entraîne au début du siècle dernier dans un Empire austro-hongrois (K.u.K.) rebaptisé pour l'occasion, par un habile jeu de mots, la Cacanie. Très tôt dans le roman, Ulrich se trouve mêlé à une grande initiative intellectuelle et politique : souligner, en 1918 , le $70^{\mathrm{e}}$ anniversaire de l'avènement de l'empereur François-Joseph. Nous sommes alors en 1913 et les travaux du comité devront prendre fin en 1914, ce qui s'avère précisément - ce que les personnages ignorent -, l'année d'entrée en guerre. Le roman met en scène une galerie de personnages, tous membres de l'organisation «l'Action parallèle » et réunis autour d'un objectif commun: découvrir l'idée directrice, l'idée sublime, l'essence - oui, la pensée rédemptrice —, qu'incarne l'Empire austro-hongrois. Il règne une grande confusion intellectuelle au sein du comité et, comme il faut que les travaux aboutissent à un dénouement au cours de l'année, il faut s'atteler à organiser le chaos. Mais travaux et délibérations s'avèrent rapidement insatisfaisants; un des personnages de la galerie, le général Stumm von Bordwehr - un militaire bien déterminé à mettre de l'ordre dans « l'esprit civil »-, posera les choses dans son langage bien à lui en déplorant que «les idées ne cessaient de déserter» (Musil 2004 [1930-1941] : 502). Les idées se contredisaient ; elles ne se laissaient pas discipliner.

Le roman non plus ne se laisse pas discipliner. Il emprunte à la philosophie, à la sociologie, et aux sciences de la nature ; il intègre essais et conversations philosophiques; il dépasse la forme du roman. Comment donc

\footnotetext{
${ }^{1}$ Dans A Far Glory (1992: 105 et suiv.), Peter L. Berger prend, par exemple le roman comme illustration de la condition moderne.
}

EUROSTUDIA - REVUE TRANSATLANTIQUE DE RECHERCHE SUR L'EUROPE 
lire un tel livre dont la forme, dirait le général Bordwehr, «traverse les lignes ennemies » ? Les auteurs du présent numéro explorent différentes possibilités de lecture.

Dans «The Occasionalist Society in Robert Musil's Novel The Man Without Qualities », l'auteur du premier texte, Andreas Anter (Universität Erfurt), entreprend de qualifier la structure de L'Homme sans qualités. Les membres de l'Action parallèle, Ulrich au premier plan, s'adonnent à une « réflexion sans fin », une discussion détachée de l'action, du réel. À l'instar du discours littéraire du romantisme politique mis en lumière par Carl Schmitt, tout événement est pour les protagonistes une «occasion » pour réfléchir. Et cette société "occasionaliste" habite un roman qui est lui-même inachevé. Renato Rodriguez-Lefebvre (Université du Québec à Montréal) entreprend quant à lui de lire le roman comme sociologie: en croisant certains des nombreux thèmes abordés par Musil dans le roman - les contacts corporels, le vêtement et la nudité - avec des écrits «proprement » sociologiques, il est en mesure de délinéer un type original de domination.

Dave Poitras (Universität Trier) choisit pour sa part de lire le roman comme source de matériaux empiriques. Il isole de façon spécifique le rapport à la nation qu'entretiennent deux des personnages, pour délinéer des positions «typiques» au contexte social décrit dans le roman. À l'aide d'un dialogue avec un autre romancier, Milan Kundera, je me penche quant à moi sur l'écriture sociologique. Kundera, lui-même lecteur de Musil, affectionne l'auteur pour son travail romanesque - sociologique, pourrait-on dire davantage que philosophique. En effet, Musil est pour lui «est un grand penseur seulement dans ses romans. Sa pensée a besoin de se nourrir des situations concrètes de personnages concrets; bref, c'est une pensée romanesque, non pas philosophique »(Kundera $1993: 276$ ).

Éclaircissement sur les classifications possibles du roman, thèmes et croisements entre les disciplines, matériau empirique, écriture sociologique : la "société opportuniste» que constituent les auteurs de ce numéro convie à réexaminer les œuvres littéraires, celle de Musil en particulier, en sociologues. Il nous faut avertir le lecteur sociologue que les nombreux fragments de L'Homme sans qualités disponibles dans les différentes éditions de l'œuvre ne sont pas sans risque de le déstabiliser: il aura l'impression de lire de la sociologie, et pourrait se demander si sa discipline ne correspondrait pas aux coulisses d'un texte littéraire, à sa forme inachevée. Un tel effet pourrait mettre 
en lumière l'intérêt aujourd'hui porté à la méthode et la théorie, souvent au détriment de la forme.

\section{Bibliographie}

Berger, P. L. (1992), "Excursus : Robert Musil and the Salvage of the Self », in A Far Glory. The Quest for Faith in an Age of Credulity. New York, The Free Press, p. 105-122.

Musil, R. (2004 [1930-1941]), L'Homme sans qualités, Paris, Éditions du Seuil.

Kundera, M. (1993), Les testaments trahis : essai, Paris, Gallimard. 